\title{
Regulatory Gaps between LNG Carriers and LNG Fuelled Ships
}

\author{
Seung-man $\mathrm{Ha}^{\mathrm{a}}$, Won-Ju Lee ${ }^{\mathrm{b} *}$, Byongug Jeong ${ }^{\mathrm{c}}$ Jae-Hyuk Choi ${ }^{\mathrm{d}}$ Jun Kang ${ }^{\mathrm{b}}$ \\ ${ }^{a}$ Korean Register, 36 Myeongji Ocean City 9-ro, Gangseo-gu, Busan, Korea \\ ${ }^{\mathrm{b}}$ Division of Marine Engineering, Korea Maritime and Ocean University, 727 Taejong-ro, Yeongdo- \\ Gu, Busan 49112, Korea \\ ${ }^{c}$ Department of Naval Architecture, Ocean and Marine Engineering, University of Strathclyde, 100 \\ Montrose Street, Glasgow, G4 OLZ, UK \\ ${ }^{\mathrm{d}}$ Division of Marine System Engineering, Korea Maritime and Ocean University, 727 Taejong-ro, \\ Yeongdo-Gu, Busan 49112, Korea \\ *corresponding author e-mail: skywonju@kmou.ac.kr, phone: +82-10-410-4262
}

\section{ABSTRACT}

Given a number of marine vessels treating the liquefied natural gas either as cargo or fuel, this paper examined the regulatory gaps of two different international Codes - the International Code of the Construction and Equipment of Ships Carrying Liquefied Gases in Bulk and the International Code of Safety for Ships Using Gases or Other Low-flashpoint Fuels - from the regulatory standpoint. Results of the gap analysis have identified and discussed the key areas encountered with regulatory discrepancies or ambiguities that might interrupt the proper design and operation of LNG carrier and LNG fuelled ship. A systematic investigation and harmonization process across the Codes was proposed to mitigate the potential issues that may arise from the discordant regulations. Also, the International Maritime Organization was suggested to take proactive action to improve such dissonances while a general insight into the importance of filling those gaps was provided for rulemakers and stakeholders.

Keywords: IGC Code, IGF Code, LNG carrier, LNG fuelled ship 


\section{Nomenclature}

BLG Bulk Liquids and Gases

BOG Boil Off Gas

CCC Carriage of Cargoes and Containers

$\mathrm{CO}_{2} \quad$ Carbon Dioxide

DWT Deadweight Tonnage

ESD Emergency Shutdown

fen collision damage factor

fl longitudinal factor

FSRU Floating Storage Regasification Units

ft Transerverse(Inboard penetration) factor

fv Vertical factor

IGC Code International Code of the Construction and Wquipment of Ships Carrying Liquefied Gases in Bulk

IGF Code International Code of Safety for Ships Using Gases or Other Low-flashpoint Fuels

IMO International Maritime Organization

ISO International Organization for Standardization

KR Korean Register

LFL Low Flammable Level

LNG Liquefied Natural Gas

MARVS Maximum Allowable Relief Valve Setting

MSC Maritime Safety Committee

$\mathrm{NO}_{\mathrm{x}} \quad$ Nitrogen Oxides

PRV Pressure Reief Valve

SIGTTO Society of International Gas Tanker and Terminal Operators

SOLAS Safety of Life at Sea 
$\mathrm{SO}_{\mathrm{x}}$

Sulphur Oxides 


\section{Introduction}

Liquefied natural gas (LNG) is a convenient form for maritime transport to markets where bulk pipelines are not technically or economically feasible (Aronson and Westermeyer 1982; Mankabady 1979). Specially-designed cryogenic marine vessels, known as LNG carriers, have been used for its transportation. Since January 1959 when the first LNG carrier, MV Methane Pioneer, (5,034 DWT) has emerged, the worldwide LNG fleet has reached 478 vessels at the end of 2017 (IGU 2018).

On the other hand, with the increasing trend of cleaner shipping, the environmental benefits of using LNG as a new source of marine fuel have been proven significant, compared to existing marine diesel fuels (Ryuichi et al. 2018). LNG fuelled ships other than gas carriers have been in service since 2000 and have consistently contributed to reducing ocean emissions such as $\mathrm{CO}_{2}, \mathrm{SO}_{\mathrm{x}}, \mathrm{NO}_{\mathrm{x}}$ and particulates (Jeong et al. 2017; Øyvind and Erikstad 2017; Rahim et al. 2016). The number of LNG fuelled ships has increased dramatically over the past few years, totalling 121 vessels in operation and 126 ships on orders as of the April of 2018 (DNVGL 2018).

LNG is a convenient form of natural gas that can reduce its volume to 1/600 times. For liquefaction, the temperature of the medium is normally maintained at around $-163{ }^{\circ} \mathrm{C}$ at atmospheric pressure in a specially-insulated cryogenic tank (Saleem et al. 2018). In the event of a leak, the liquid would rapidly evaporate when exposed to normal atmospheric conditions. This rapid phase transition can pose a direct danger to humans. In particular, cryogenic temperatures cause burns to nearby people, and massive vaporisation suffocates to anyone in a confined space. Leaky media can also cause severe damage to the ship structure, such as structural embrittlement, when it touches a ship hull.

On the other hand, people can obscure the fact that LNG is a more dangerous substance that can be fired or exploded if given the opportunity to ignite. The type of fire and explosion may depend on the surrounding conditions on whether open or confined. Although the probability of a fire or explosion is lower than the direct risks, the consequences of such an accident are tremendously high. Given the risk that can be expressed as a combination of the probability and the consequence, the safety issues associated with the transport or use of LNG for marine purposes must be understood and handled properly.

Not surprisingly, in an effort to enhance the safety of LNG handling, International Maritime Organization (IMO) has developed two international Codes: International Code of the Construction and Equipment of Ships Carrying Liquefied Gases in Bulk (IGC Code), in 1986 and subsequent 
amendments in 1994 and 2014 and International Code of Safety for Ship Using Gases or Other Lowflashpoint Fuels (IGF Code), which came into force on 01 January 2017.

\subsection{IGC Code}

The IGC Code, firstly adopted in 1983, has been uniformly applied to LNG carriers engaged in international voyages. It provides the international standards for the safe transport of liquefied gases and other specified substances stated in Chapter 19 of the IGC Code through maritime transport routes to minimise risks to ships, crew and the environment. To meet recent technical trends, the IGC Code has undergone a significant revision to safety requirements related to the location of cargo tanks, personnel, fire protection, turret compartment, etc. in 2014. Figure 1 summarises the brief history of the IGC Code.

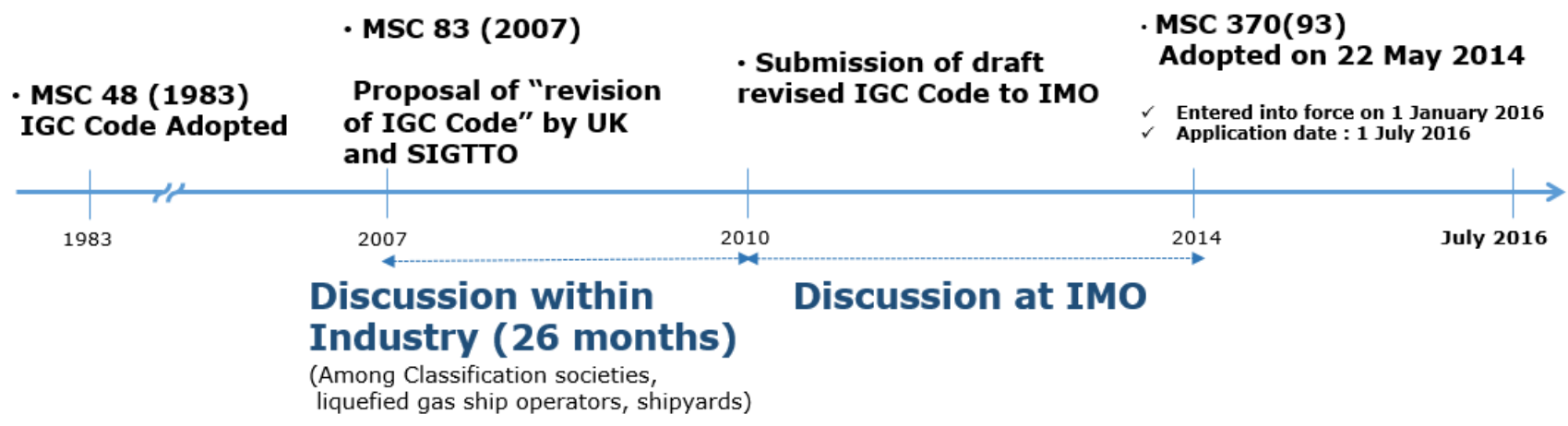

Figure 1. Timeline of IGC Code.

\subsection{IGF Code}

Until the 21st century, there was no safety regulation for LNG fuelled ships other than LNG carriers. Due to the remarkable growth of ships using LNG fuels backed by stringent environmental regulations, it became an urgent matter to develop a unified international Code. In this context, IMO's Maritime Safety Committee (MSC) began developing new regulations in 2004 to ensure the safety of LNG fuel vessels. As a result, IMO Res.MSC.286 (85) (IMO 2009) - Interim Guidelines on Safety for Natural Gas-fuelled Engine Installations in Ship was adopted in 2009. For the next phase of work, the IGF Code has entered into force on the $1^{\text {st }}$ of January 2017 . This Code particularly deals with mandatory provisions for the arrangement, installation, control and monitoring of machinery, 
equipment and systems for using low-flash point fuels which can be applied for LNG fuelled ships to minimize the risk to the ship, its crew and the environment, taking into account the nature of the fuel concerned (IMO 2015c). As of 2017, the IGF Code is to be applied to approximately 200 LNG fuelled ships in various ship types such as passenger ships, tankers and bulk carriers, container ships, dry cargo vessels, service and supply vessels, car/passenger ferries, PSVs, and Ro-Ro vessels. (Corkhill 2017). The timeline of IGF Code is summarized in Figure 2.

- MSC 78 (2004)

Norway's proposal

Natural Gas fuelled ship's regulation
MSC 95 (2015)

IGF Code (Natural Gas only) was adopted

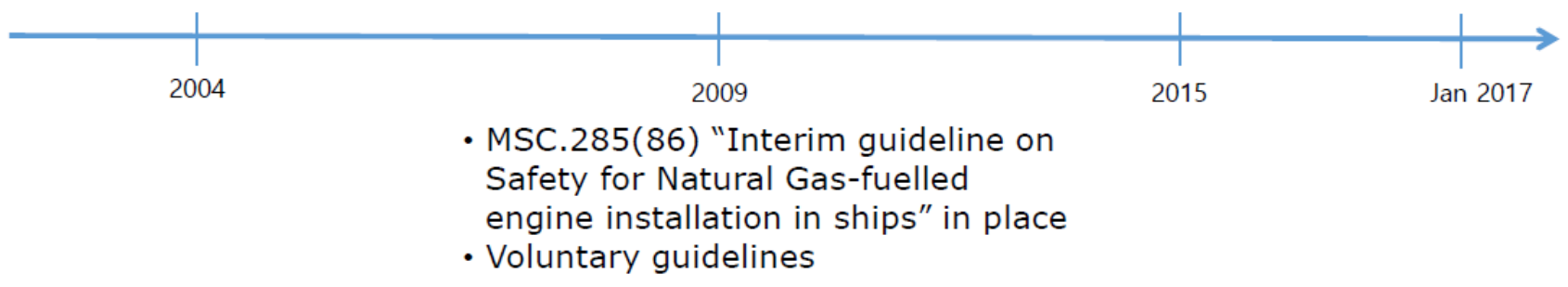

Figure 2. Timeline of IGF Code.

While developing the two codes, there have been several issues. In the meeting of IMO Sub-Committee on Bulk Liquids and Gases (BLG), at its fifteenth session, it was addressed that the draft of two codes, particularly, the safety requirements of engine rooms, should be harmonised as recognising that the IGF Code has broader implications for using LNG as fuel rather than cargo. For regulatory harmonisation, the BLG had to establish a joint correspondence group (IMO 2011e; IMO 2012a). In the development of the IGF Code, it has been stated that the Code should be aligned with the draft revised IGC Code as much as possible because many parts of LNG fuelled ships are very analogous to the counterparts of LNG carriers (IMO 2011a, 2011b, 2011e; IMO 2012a). However, since the two Codes were developed at similar times, the unification works failed to be made properly. Moreover, different working groups in IMO were so dedicated to each code that the safety requirements of the two Codes were deemed to diverge. Under this circumstance, the correspondence group had to concede that it was difficult to seek alignment in the condition that one of them was almost finalised, whereas the other was still under development (IMO 2011d; IMO 2012a). At MSC 92, it has been agreed that the new IGC Code should not set a precedent for the IGF Code while their relationship would be discussed once the two codes are finalised (IMO 2013b). Given that, at MSC 95, the IGF Code was adopted (IMO 2015c). 
It is worth noting that any ship using low-flash point fuel is required to comply with either the IGC or the IGF Code but they can't both applied to the same ship. i.e. Gas carriers will be exempted from the application of the IGF Code.

As can be seen from the Figure 3, except for the engine room, LNG fuelled ships and LNG carriers have different functions, layout and design features and risks to some extent, which is why it is necessarily to have separate regulations. Nonetheless, the regulatory differences still can confuse stakeholders since they have considerable similarities but also areas of inconsistencies, particularly engine room systems. The potential for future inconsistency, misinterpretation and misunderstanding of regulations in a fast expanding sector of the industry would inevitably lead to an increase in incidents which would threaten both ship and human lives in addition to legal allegations. Therefore, the necessity of actions to be taken in order to avoid such outcomes is paramount.

Based on the background above, the aim of this paper was to compare and contribute to harmonizing these codes by identifying the regulatory gaps between the IGC Code and the IGF Code.

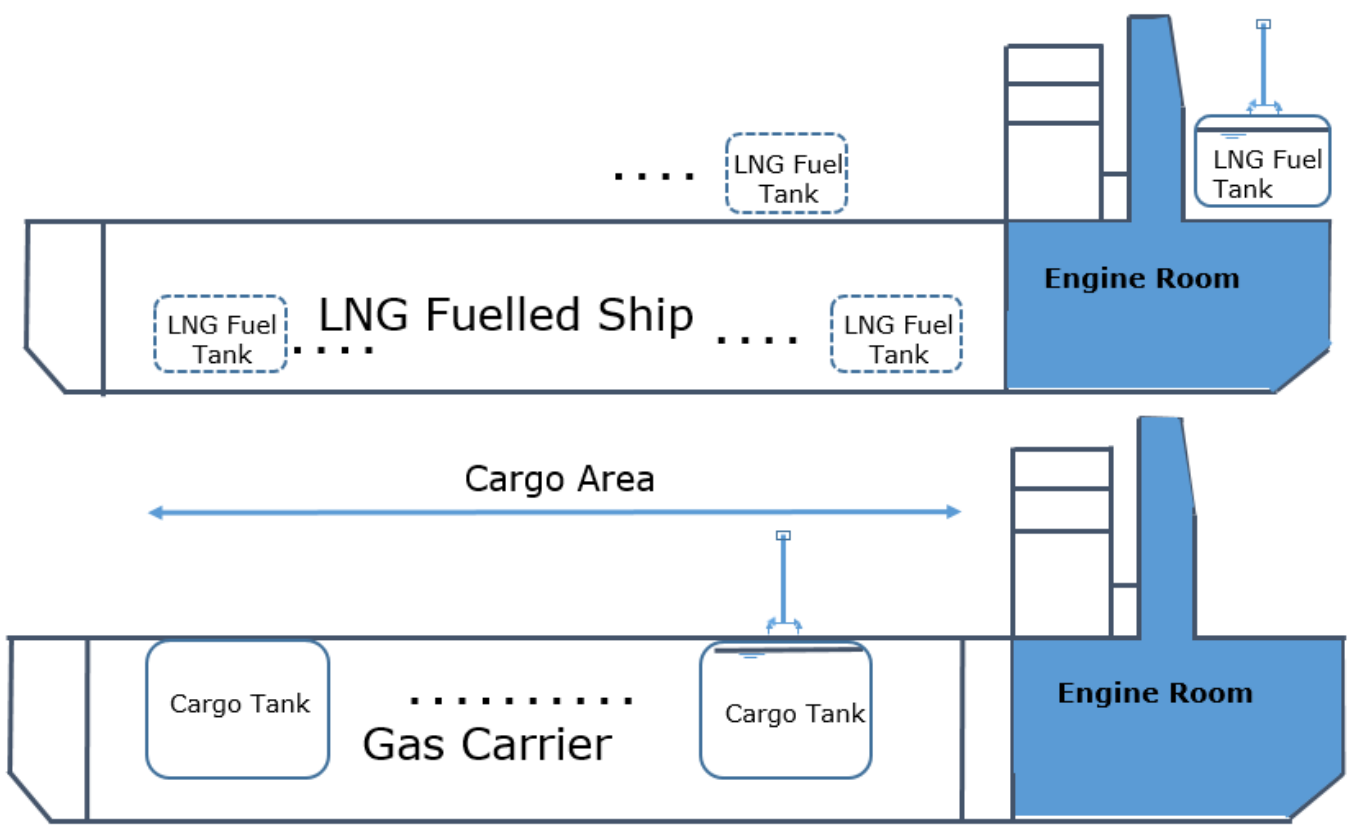

Figure 3. Brief arrangements of LNG fuelled ship and LNG carrier. 


\section{Research method}

As the approach to conducting the comparative analysis, first of all, the two Codes were examined chapter by chapter as shown in Table 1 . Then, in order to draw a comprehensive understanding of the history and the technical background of the two Codes, this paper reviewed most of the IMO documentations and working group reports associated with the development of these Codes. The know-how gained through the implementation of Korean Register projects and feedback received from stakeholders, particularly the shipowners and shipyards were used for this analysis. As a process of the gap analysis, the safety requirements of the IGC Code were applied to a 180K LNG carrier and a 7.5K small LNG bunkering vessel, and those of the IGF Code were applied to an LNG fuelled 50K DWT bulk carrier and a 325K LNG fuelled ore carrier.

Table 1. Chapters matching for the IGC and IGF Codes.

\begin{tabular}{|c|c|c|c|}
\hline \multicolumn{2}{|r|}{ IGC Code } & \multicolumn{2}{|r|}{ IGF Code } \\
\hline \multirow[t]{2}{*}{ Ch.1 } & \multirow[t]{2}{*}{ General } & \multirow{2}{*}{$\begin{array}{l}\text { Ch. } 2 \\
\text { and } 4\end{array}$} & 2. General \\
\hline & & & 4. General requirement \\
\hline Ch. 2 & $\begin{array}{l}\text { Ship survival capability and } \\
\text { location of cargo tanks }\end{array}$ & Ch. 5 & $\begin{array}{l}\text { 5.3 Regulation - General i.e. tank location } 5.3 \\
\text { Regulation - General i.e. tank location }\end{array}$ \\
\hline Ch. 3 & Ship arrangements & Ch. 5 & 5. Ship design and arrangement \\
\hline Ch. 4 & Cargo containment & Ch. 6 & 6. Fuel containment system \\
\hline Ch. 5 & $\begin{array}{l}\text { Process pressure vessels and } \\
\text { liquids, vapour and pressure } \\
\text { piping systems }\end{array}$ & $\begin{array}{l}\text { Ch. 5, } \\
7 \text { and } \\
8\end{array}$ & $\begin{array}{l}5.7 \text { Reg. for location and protection of fuel } \\
\text { piping } \\
7.3 \text { Reg. for general pipe design } \\
8 \text { Bunkering }\end{array}$ \\
\hline Ch. 6 & $\begin{array}{l}\text { Materials of construction and } \\
\text { quality control }\end{array}$ & Ch. 7 & 7.4 Regulation for materials \\
\hline Ch. 7 & $\begin{array}{l}\text { Cargo pressure/Temperature } \\
\text { control }\end{array}$ & Ch. 6 & $\begin{array}{l}6.9 \text { Reg. for maintaining of fuel storage } \\
\text { condition }\end{array}$ \\
\hline Ch. 8 & $\begin{array}{l}\text { Vent systems for cargo } \\
\text { containment }\end{array}$ & Ch. 6 & 6.7 Reg. for pressure relief system \\
\hline
\end{tabular}




\begin{tabular}{|c|c|c|c|}
\hline Ch. 9 & $\begin{array}{l}\text { Cargo containment system } \\
\text { atmosphere control }\end{array}$ & Ch. 6 & $\begin{array}{l}6.10 ~ 12 \text { Reg. on atmospheric/ environmental } \\
\text { control within the fuel containment system/ fuel } \\
\text { storage hold space } \\
6.13 \text { Reg. on inerting } \\
6.14 \text { Reg. on inert gas production and storage } \\
\text { on board }\end{array}$ \\
\hline Ch. 10 & Electrical installations & $\begin{array}{l}\text { Ch. } 12 \\
\text { and } 14\end{array}$ & $\begin{array}{l}12 \text { Explosion } \\
14 \text { Electrical installations }\end{array}$ \\
\hline Ch. 11 & Fire protection and extinction & Ch. 11 & 11 Fire safety \\
\hline Ch. 12 & $\begin{array}{l}\text { Artificial ventilation in the cargo } \\
\text { area }\end{array}$ & Ch. 13 & 13 Ventilation \\
\hline Ch. 13 & $\begin{array}{l}\text { Instrumentation and automation } \\
\text { systems }\end{array}$ & Ch. 15 & 15 Control, monitoring and safety system \\
\hline Ch. 14 & Personnel protection & Ch. 18 & 18 Operation \\
\hline Ch. 15 & Filling limits for cargo tanks & Ch. 6 & $\begin{array}{l}6.8 \text { Reg. on loading limit for liquefied gas fuel } \\
\text { tanks }\end{array}$ \\
\hline Ch. 16 & Use of cargo as fuel & $\begin{array}{l}\text { Ch. } 5 \text {, } \\
9 \text { and } \\
10\end{array}$ & $\begin{array}{l}\text { 5.4 Machinery concept } \\
\text { 9. Fuel supply to consumers } \\
\text { 10 Power generation including propulsion and } \\
\text { other gas consumers }\end{array}$ \\
\hline Ch. 17 & Special requirements & $\mathrm{N} / \mathrm{A}$ & N/A \\
\hline Ch. 18 & Operating requirements & Ch. 18 & 18 Operation \\
\hline Ch. 19 & $\begin{array}{l}\text { Summary of minimum } \\
\text { requirements }\end{array}$ & N/A & N/A \\
\hline
\end{tabular}




\section{Gap Analysis between IGF Code and IGC Code}

In this section, a gas analysis identifying the differences or discrepancies of the safety requirements for LNG carriers and LNG fuelled ships in accordance with the IGC and the IGF Codes is provided. There are differences between both Codes which are not necessary considered as discrepancies since some of these differences are justified due to the change of the functions, sizes, application environment, and risks.

\subsection{Risk assessment}

According to the IGC Code 1.1.10, while not specifically required to LNG carriers, risk assessment is commonly applied to the floating storage regasification units (FSRUs) and ships operating for the purpose of receiving, processing, liquefaction and storage of gas. It is also stipulated in IGF Code 4.2 and applied to the particular areas of LNG fuelled ships: sizing of drip trays; design of airlocks; liquefied gas containment system; determination of additional relevant accidental load scenarios; design and arrangements for bunkering station; alternative calculations for ventilation capacity for tank connection space; provision of gas detectors; and limit state design (IMO 2015b, 2015d).

\subsection{Machinery space concept}

The machinery space in which gas engines are installed and operated is particularly prone to accidents of fire and explosion. According to the IGF Code 5.4, LNG fuelled ships are supposed to meet one of the two machinery concepts: either 'gas safe machinery space' or 'ESD protected machinery space' (IMO 2015c).

In the concept of the gas safe machinery space, any single fault is not allowed to cause the gas release into the machinery space. Therefore, preventive measures such as double-walled piping systems must be applied to capture the leaked gas.

Unlike the gas safe machinery space, the gas leakage can be released into the engine room under the concept of the ESD protected machinery space in the event of such an accident. Instead, the entire machinery space affected by the initial release must be isolated without losing propulsion power. To 
meet this requirement, two identical machinery spaces need to be segregated, meaning that any common boundary is not allowed (IMO 2015c). The conceptual designs for both spaces are described in Table 2.

Table 2. Conceptual designs for the machinery spaces.

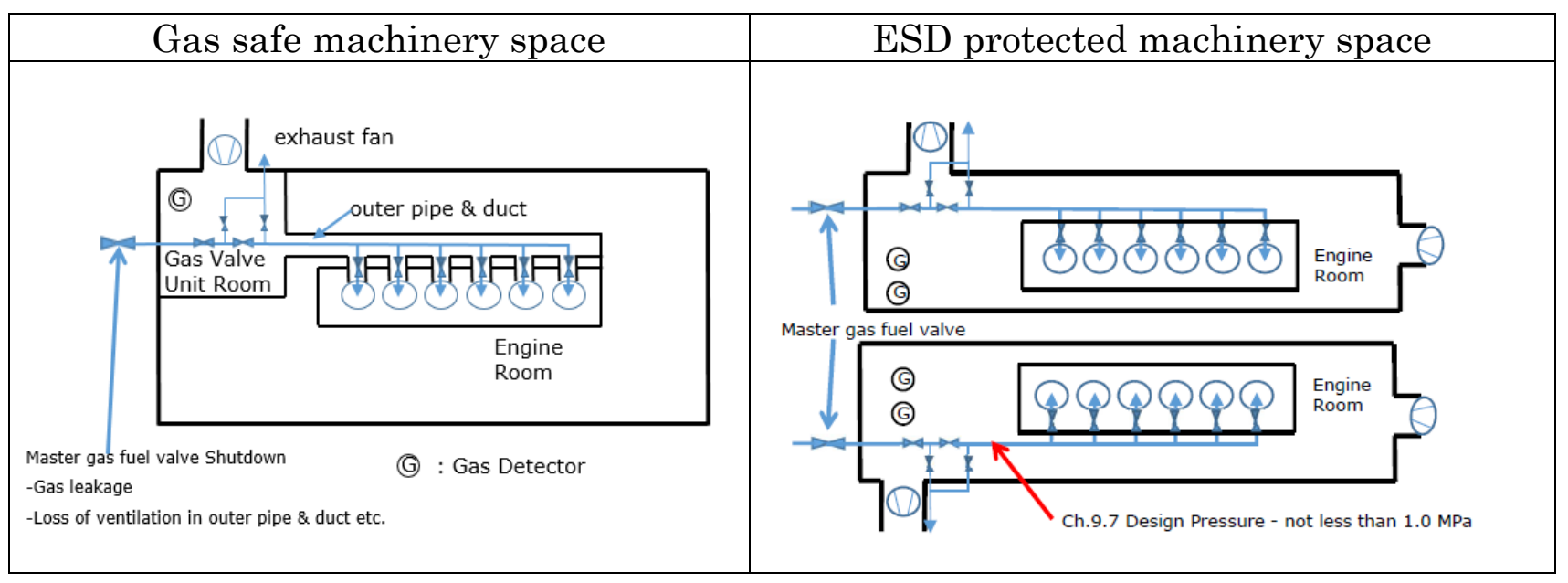

Meanwhile, a regulatory disparity was identified: while both machinery spaces are applicable to LNG fuelled ships based on the IGF Code, the IGC Code only accepts the concept of the gas safe machinery space for LNG carriers.

The gas safe machinery space is so designed to ensure the absolute prevention from initiating gas leak. On the other hand, the ESD protected machinery space is focused on the post-treatment of the initial gas leak. Given the fact, it may be credible to think that the gas safe machinery space is inherently more reliable than the ESD protected machinery space. Consequently, the IMO Sub-Committee on Bulk Liquid and Gases (BLG) agreed that the use of the ESD machinery space concept would not be suitable for the gases heavier than air or having low-flash points (IMO 2011c). Nonetheless, given that the gas engines used for both types of vessels are identical, there still leaves ambiguity as to why ESDprotected engine spaces are acceptable for LNG fuelled ships and why they are not for LNG carriers.

Also, the IGF Code 9.7 limits the pressure of the gas fuel supply system for gas engines in the ESD protected machinery space to 10 bar. This provision technically restricts the use of all two-stroke gas engines that have pretty much higher fuel gas pressures than the threshold (Fernandez et al. 2017). 


\subsection{Fuel containment system (LNG storage tank)}

There are four main types of LNG fuel tanks used on board at present: one is a membrane type (integrated into hull structure), and the others are independent types A, B and C respectively. Although LNG cargo storage tanks and fuel containment systems are identical, regulatory discrepancies have been found in various parts of the safety requirements.

\subsubsection{Tank location}

Both Codes provide specific guidelines on LNG tank location to secure the LNG tank from external damages such as collision and grounding by keeping the minimum distance of the LNG tank from the ship side and bottom hull. The safety distance is determined in accordance with the hazardous levels of the liquid stored in the tank expressed as Type $1 \mathrm{G}, 2 \mathrm{G}$ and $3 \mathrm{G}$; Type $1 \mathrm{G}$ is regarded the most hazardous cargos whereas 3G is the least hazardous ones (IMO 2014c).

The IGC Code categorises the LNG cargo into Type $2 \mathrm{G}$, thereby the safety requirements for the Type $2 \mathrm{G}$ tank is applicable to LNG carriers. On the other hand, the IGF Code groups the LNG fuel into the Type 1G, therefore the LNG fueled tank are subject to the Type $1 \mathrm{G}$ requirements (IMO 2013b). Table 3 summarises the guidelines on establishing the safety distance stated in the IGC and IGF Codes; it is entirely credible to point out that the safety requirements for IGF Code are more strictly regulated than the IGC Code (IMO 2011c).

Table 3. Requirements for tank location in a deterministic approach.

\begin{tabular}{|c|c|c|}
\hline No. & Tank location & Requirements \\
\hline \multicolumn{3}{|c|}{ IGC Code (Ch.2.4) } \\
\hline \multicolumn{2}{|c|}{ Distance from side shell (Type 2G) } & $0.8 \sim 2 \mathrm{~m}$ \\
\hline \multicolumn{3}{|c|}{ IGF Code (Reg. 5.3.3) } \\
\hline 1 & $\begin{array}{l}\text { Transverse distance from Ship } \\
\text { side }\end{array}$ & $\begin{array}{l}\text { Ship breadth } / 5 \mathrm{~m} \text { or } 11.5 \mathrm{~m} \text {, whichever } \\
\text { is less at summer load water line }\end{array}$ \\
\hline 2 & Distance from side shell & $0.8 \sim 2 \mathrm{~m}$ \\
\hline 3 & Longitudinal location & abaft the collision bulkhead \\
\hline 4 & $\begin{array}{l}\text { Vertical distance from bottom } \\
\text { shell }\end{array}$ & $\begin{array}{l}\text { Ship breadth/15 m or } 2.0 \mathrm{~m} \text {, whichever } \\
\text { is less }\end{array}$ \\
\hline
\end{tabular}




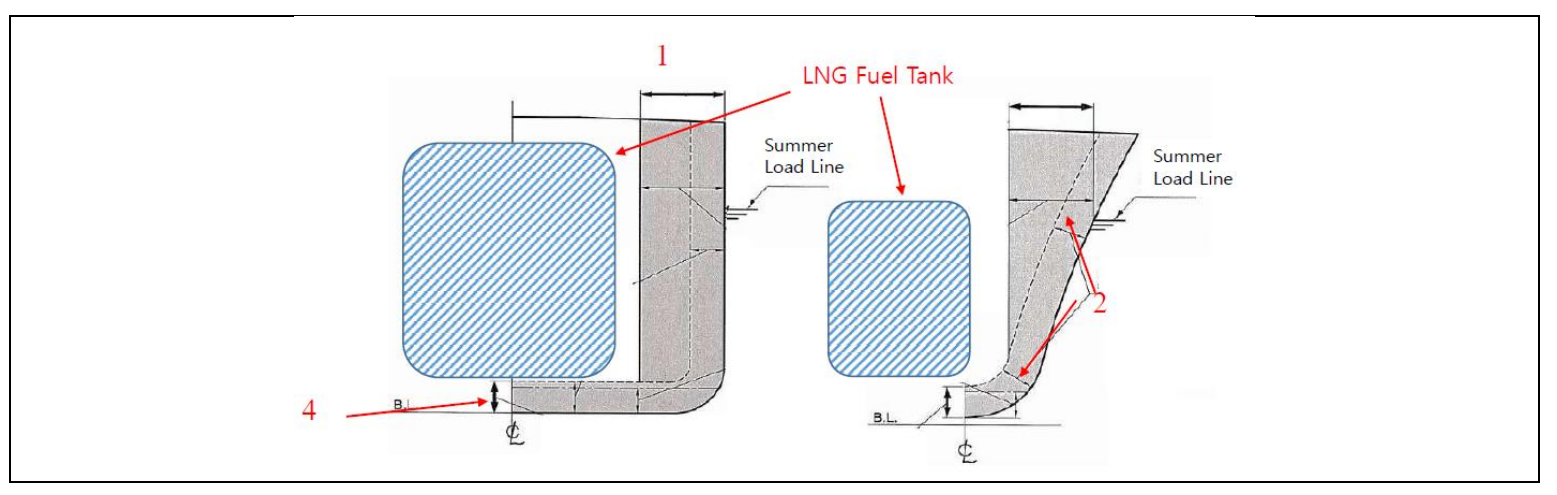

As an alternative, the probabilistic approach to the distance of the LNG tank can be more flexibly deployed without reducing the safety aspect. In this context, the IGF Code 5.3.4 alone introduced the probabilistic approach to determine the safety distance using the concept of the damage stability analysis in accordance with SOLAS II-1 (IMO 2013a; IMO 2014a, 2014b). About this, transverse distance from shipside can be considered using Eq. (1).

$$
\mathrm{f}_{\mathrm{CN}}=\mathrm{f}_{1} \cdot \mathrm{f}_{\mathrm{t}} \cdot \mathrm{f}_{\mathrm{v}}
$$

Where, $f_{\mathrm{CN}}$ is the parameters to be included in a simplified assessment of probability for hitting the tank in a collision ( $f_{\mathrm{CN}}$ shall be less than 0.02 for passenger ships and 0.04 for cargo ships); $\mathrm{f}_{1}$ is the longitudinal factor; $\mathrm{f}_{\mathrm{t}}$ is the inboard penetration factor; and $\mathrm{f}_{\mathrm{v}}$ is the vertical factor.

Given that whether it is a form of cargo or fuel, the storage of the LNG in a vessel is technically same and there may be no or inconsequential difference in the potential risk associated with mechanical and external damages, the regulatory disparity is contrary to what our common knowledge tells us; that is the equal level of safety requirements should be affixed in both Codes.

\subsubsection{An arrangement of tank pipe connection}

Table 4 summarizes the results of the comparative analysis of tank pipe connections.

Table 4. Requirements for tank pipe connection 


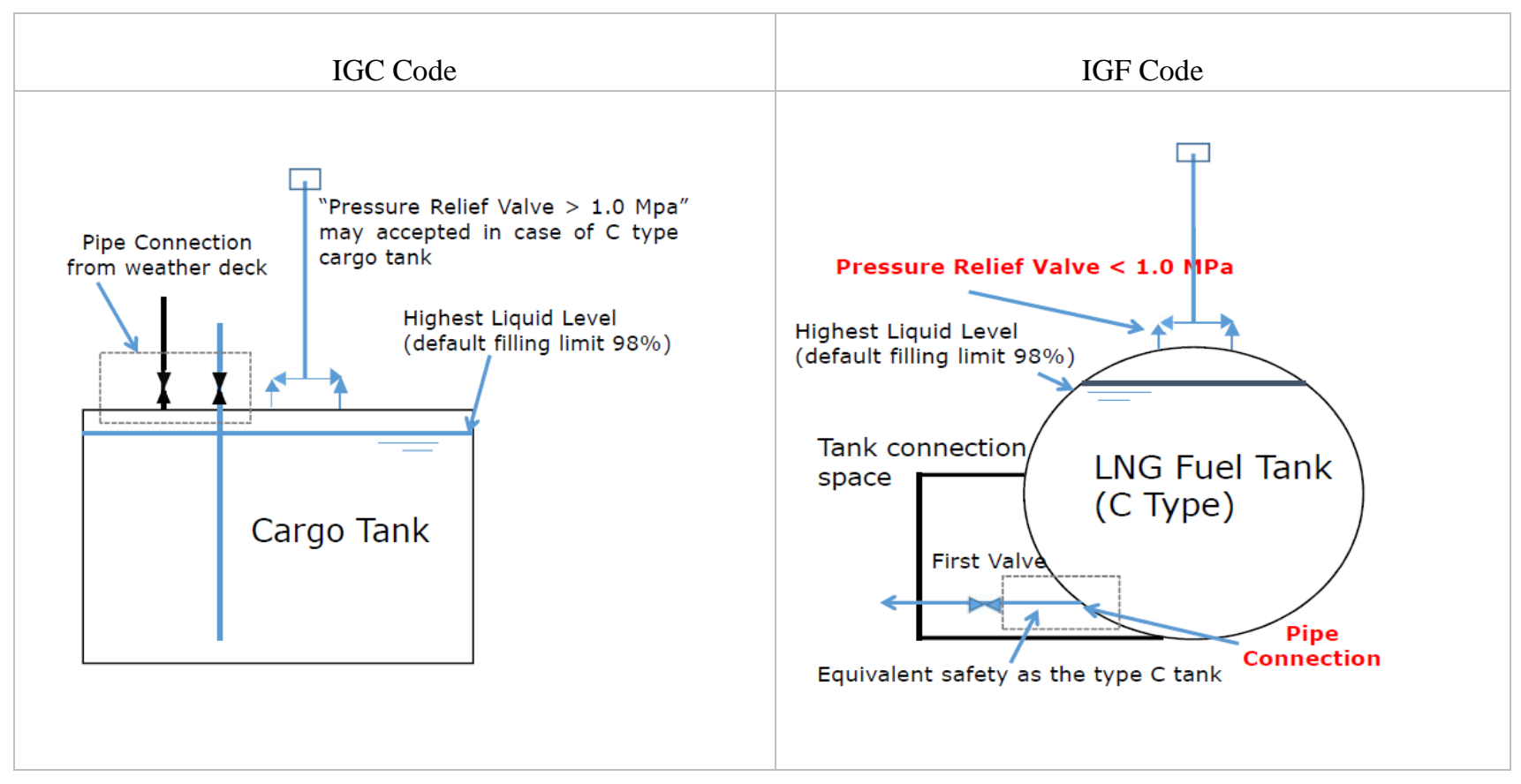

The key differences are described as below:

- The IGF Code 6.3.1 requires that the maximum allowable relief valve setting (MARVS) be 1.0 $\mathrm{MPa}$ or less regardless of tank type. In the IGC Code 4.23, the setting pressure for type $\mathrm{C}$ tank can be set 1.0MPa or higher.

- Pipes mounted on the head of the LNG cargo tank are to be fitted above the highest LNG level in the tanks (IGC Code 5.5.2.1); if using type $\mathrm{C}$ fuel tank having the tank connection space, the pipes can be connected below the highest liquid level following the IGF Code 6.3.5.

The concept of the tank connection space described in the IGF Code is compared to the equivalence of the IGC Code in Table 5. According to the IGF Code 6.3.4, if the tank connection space is not on the open deck, all connection systems - piping, fittings, flanges, tank valves, etc. - are to be exclusively arranged within the tank connection space or what is so-called 'Cold Box' which are to be designed to seize the LNG leakage if any. Meanwhile, in the LNG carriers, all piping systems connected to the cargo tank is to be directed from the weather decks(IGC Code 5.2.2.1.3)(IMO 2015c).

The differences of safety requirement for tank pipe connection between the IGF and IGC Codes may not lead to significant controversy in ship design, construction and operation. However, this information and justification are believed to help stakeholders to gain a better understanding during applications of the two Codes. 
Table 5. Concept of tank pipe connection.

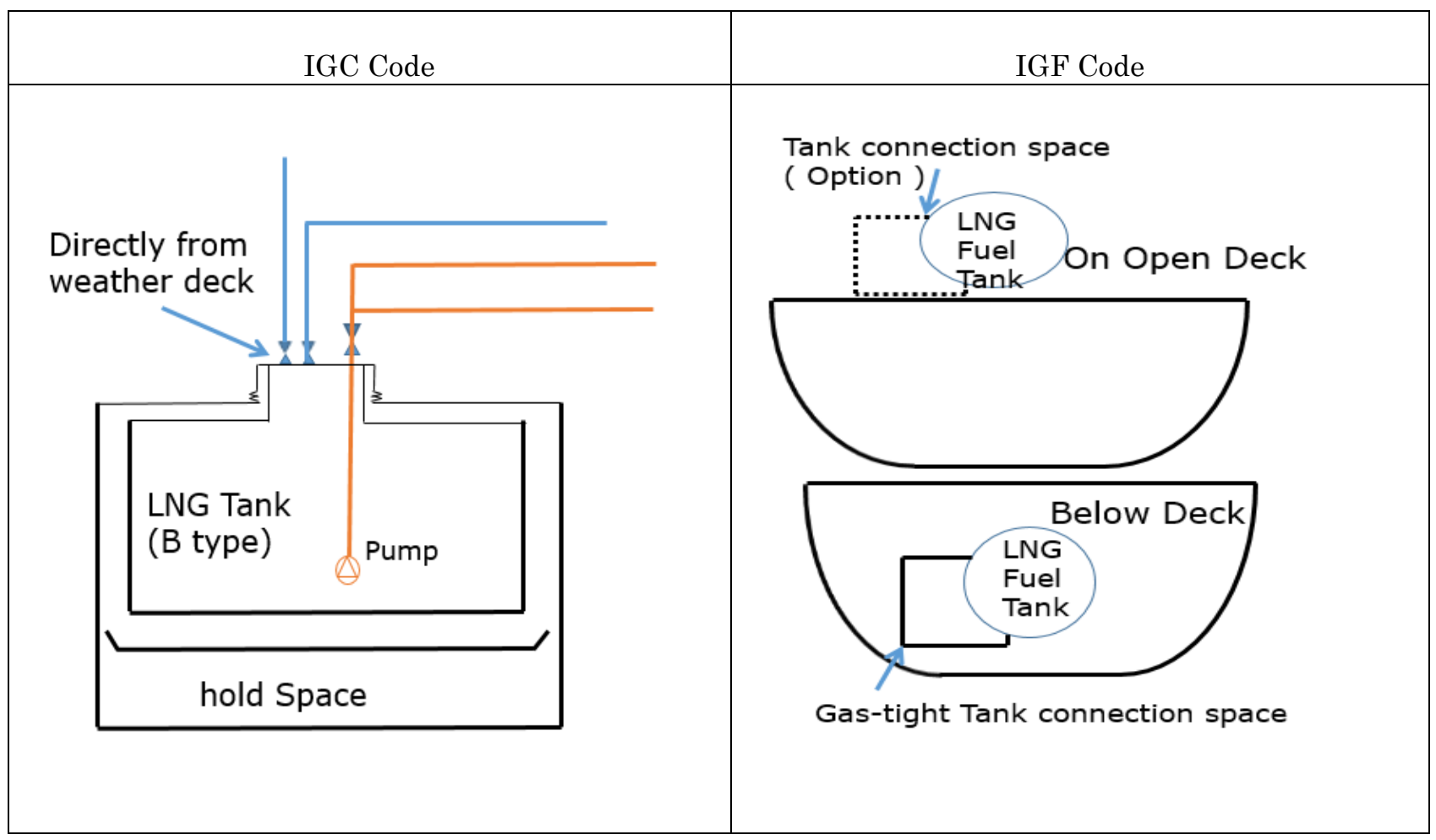

\subsubsection{Arrangement of pressure relief system}

In order to prevent the unwanted gas release out of the pressure relief valve (PRV) from escalating incidents, each code provides the safety requirements for arranging the PRVs in different ways which are described in Table 6.

Table 6. An arrangement of pressure relief system. 


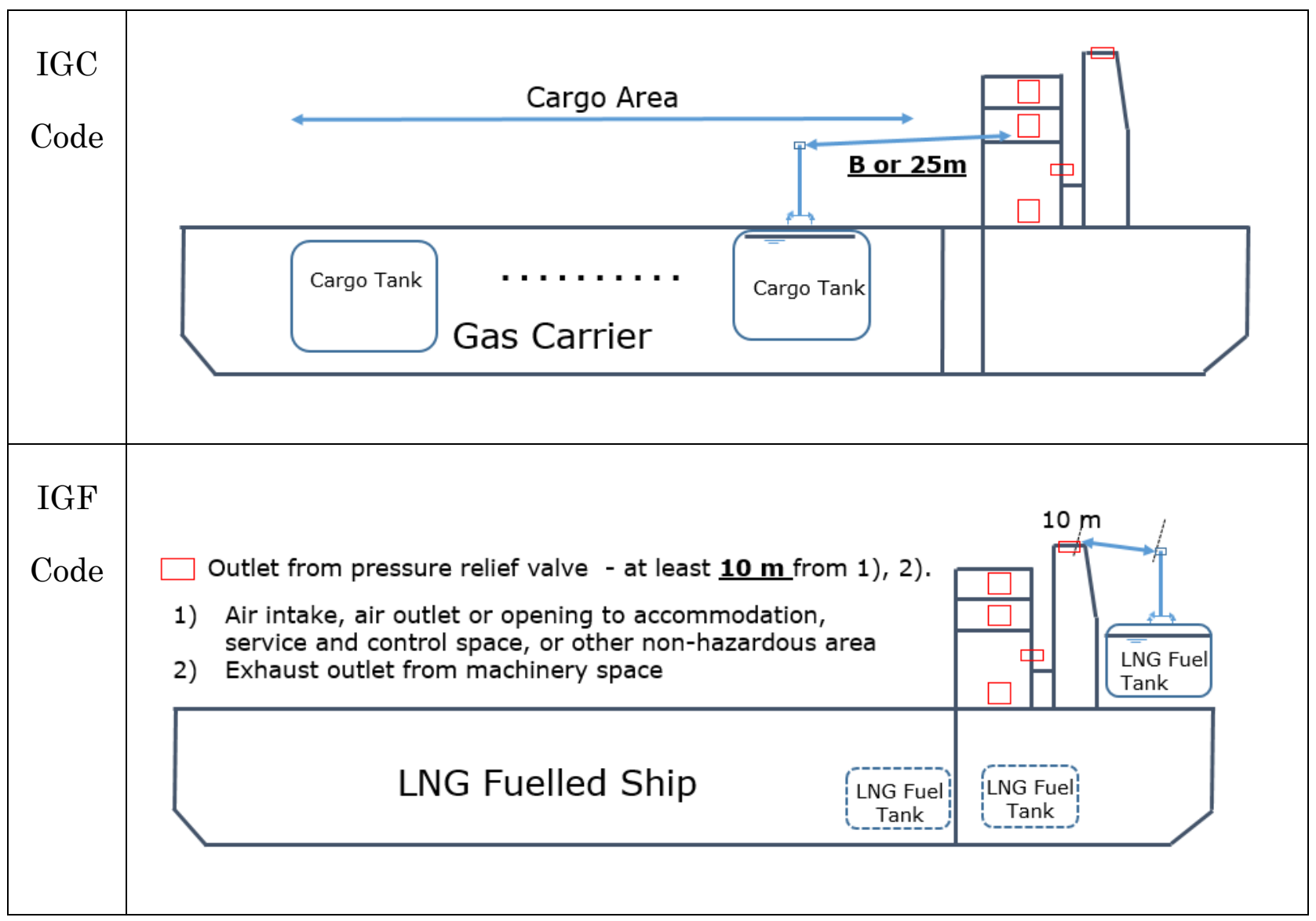

The key differences are described as below:

- IGC Code 8.2.11.1 demands that the outlet from the cargo pressure relief valve (PRV) be arranged at least $10 \mathrm{~m}$ distance from the nearest - air intake, air outlet or opening to accommodation spaces, service spaces and control stations, or other non-hazardous areas - or equal to ship breadth or $25 \mathrm{~m}$, whichever is less.

- IGF Code Part A-1, 6.7.2.8 requires the outlet from the pressure relief valves should be placed at minimum $10 \mathrm{~m}$ distance from the non-hazardous areas, such as service and control spaces, air intake and outlet or opening to accommodation and exhaust outlet from machinery installations.

Although both Codes require the safety distances from the non-hazardous areas, the level of such distances is divergent based on whether they are fuel tanks or cargo tanks (IMO 2014c; IMO 2015c). This regulatory discrepancy needs to be justified in a clearer way through systematic studies on investigating the adequacy and inadequacy of both codes. 
For an example of the IGF Code, the safety distance of $10 \mathrm{~m}$ may be not applicable to small ships; 10 $\mathrm{m}$ distance may be not significant for large ships, while it may be for small ships. Therefore, it was of a view that the degree of safety requirements of the IGF Code should be coupled with a risk-based approach rather than the size of the ship.

\subsubsection{Control of tank pressure and temperature}

To control of tank pressure, temperature and Boil Off Gas (BOG) in both Codes, one of the following methods should be applied with design range: re-liquefaction and thermal oxidation(combustion) of the vapour, liquefied gas fuel cooling or pressure accumulation (IMO 2014c; IMO 2015c). Table 7 indicates the relative applicability of the four methods with the sample of Type C LNG fuel tank and membrane cargo tank which are most widely applied tanks to data. The term "applicability" is used to measure how the proposed method is compatible with actual operating characteristics.

It is viewed that the difference in the relief valve setting values of the tank led to the different applicability in terms of the methods of re-liquefaction of vapour and pressure accumulation.

According to the IGF Code 6.9.1.1, the pressure and temperature of the LNG fuel tanks should be controlled and maintenance for a period of minimum 15 days after the initial activation of these safety systems. Such requirements are not stated in the IGC Code for LNG cargo tanks (IMO 2016c).

Table 7. Applicability of control system for tank pressure and temperature

\begin{tabular}{|c|c|c|c|c|}
\hline & Methods & Equipment & $\begin{array}{c}\text { IGF Code } \\
\text { (C Type Fuel Tank) }\end{array}$ & $\begin{array}{c}\text { IGC Code } \\
\text { (Membrane Tank) }\end{array}$ \\
\hline 1 & Re-liquefaction of vapour & Re-liquefaction System & $\sqrt{ }$ & $\sqrt{ } \sqrt{ }$ \\
\hline \multirow[t]{2}{*}{2} & \multirow[t]{2}{*}{ Thermal oxidation of vapour } & $\begin{array}{c}\text { Internal Combustion Engines, } \\
\text { Boilers, Gas Turbines }\end{array}$ & $\sqrt{ } \sqrt{ }$ & $\sqrt{ } \sqrt{ }$ \\
\hline & & Gas Combustion Unit & $\sqrt{ }$ & $\sqrt{ } \sqrt{ }$ \\
\hline 3 & Pressure accumulation & Pressure Relief Valve, Insulation & $\sqrt{ } \sqrt{ }$ & $\sqrt{ }$ \\
\hline 4 & Liquefied gas fuel cooling & Cooling Coil & $\mathrm{n} / \mathrm{a}$ & $\mathrm{n} / \mathrm{a}$ \\
\hline
\end{tabular}




\subsection{Safety systems}

In this part, the gas analysis identifying the difference or discrepancies of the safety requirement related to fire safety, ventilation system, piping design, etc. between is provided.

\subsubsection{Piping design}

Since LNG is a cryogenic media, the piping system for transferring this liquid is carefully designed. Both codes commonly require the piping systems with the design temperature lower than minus $110^{\circ} \mathrm{C}$ or colder to be subject to the stress analysis (IMO 2014c; IMO 2015c).

However, the IGF Code additionally requires that the piping systems with the maximum working pressure of 1.0 MPa or higher, regardless of the design temperature, are subject to such analysis (IMO 2015c). This means that the fuel supply piping systems for two-stroke gas engines applied to LNG fuelled ships are subject to the stress analysis while the same systems are not subject to the analysis when mounted on LNG carriers. The risk of the gas leak from high-pressure pipes is critical, potentially leading to an increase in accidents associated with the safety of ships, its crew and the marine environment. Given this, it was of our view that the stress analysis for the high-pressure piping system is to be carried out regardless of the ship types. Therefore, the update of the IGC Code is necessary.

Additional differences pertinent to the arrangement of LNG piping systems between the two codes are described in Error! Reference source not found. (IMO 2014c; IMO 2015c).

Table 8. Safety requirements for LNG piping systems.

\begin{tabular}{|c|c|c|}
\hline Items & IGC Code & IGF Code \\
\hline $\begin{array}{l}\text { Double Wall Piping system in gas } \\
\text { safe machinery spaces }\end{array}$ & $\begin{array}{l}\text { - Ventilated air (30 air changes/hour) } \\
\text { - Inert gas (e.g. nitrogen) }\end{array}$ & $\begin{array}{l}\text { - Ventilated air (30 air changes/hour) } \\
\text { - Inert gas (e.g. nitrogen) } \\
\text { - Other solution providing an equivalent } \\
\text { safety level, e.g. Vacuum - especially for } \\
\text { LNG }\end{array}$ \\
\hline $\begin{array}{l}\text { Duct or outer pipe containing high- } \\
\text { pressure gas piping system }\end{array}$ & NIL & $\begin{array}{l}\text { pipes with design temperature lower than } \\
-55^{\circ} \mathrm{C}\end{array}$ \\
\hline Duct or Outer pipe around LNG fuel & NIL & Pipes with design temperature lower than \\
\hline
\end{tabular}




\begin{tabular}{|l|l|l|}
\hline piping system & & $-165^{\circ} \mathrm{C}$ \\
\hline
\end{tabular}

\subsubsection{Water spray system}

In terms of the regulations on the water spray system as a fixed fire-fighting system, the summary of the gap analysis is illustrated in Table 9. The major difference lies in the scope of the areas to be protected.

The IGC Code stipulates that exposed boundaries facing the cargo area, such as deckhouses and bulkheads of superstructures, should be covered by the water spray system. Besides, various other areas to be protected by the system are defined in the IGC Code 11.3.1 (IMO 2014c).

The coverage of the water spray system is relatively narrow for the LNG fuelled ships, compared to that for LNG carriers due to the extent of the hazards and the tank size limitation. Meanwhile, taking into account that the LNG fuel tank can be arranged in many different ways, the ship structures in the vicinity of the fuel tank may be exposed to the fire risk; the effect of fire near the LNG fuel tank can be minimized by segregating the LNG fuel tank on open decks from the boundaries of various hazardous and non-hazardous areas such as superstructures, compressor rooms, pump-rooms, cargo control rooms, bunkering control stations, bunkering stations, and deck houses. In this philosophy, the IGF Code 11.5.2 stipulates that the water spray system is installed for all fuel tanks placed less than $10 \mathrm{~m}$ away from such boundaries (IMO 2015c).

Table 9. Safety requirements for LNG piping systems.

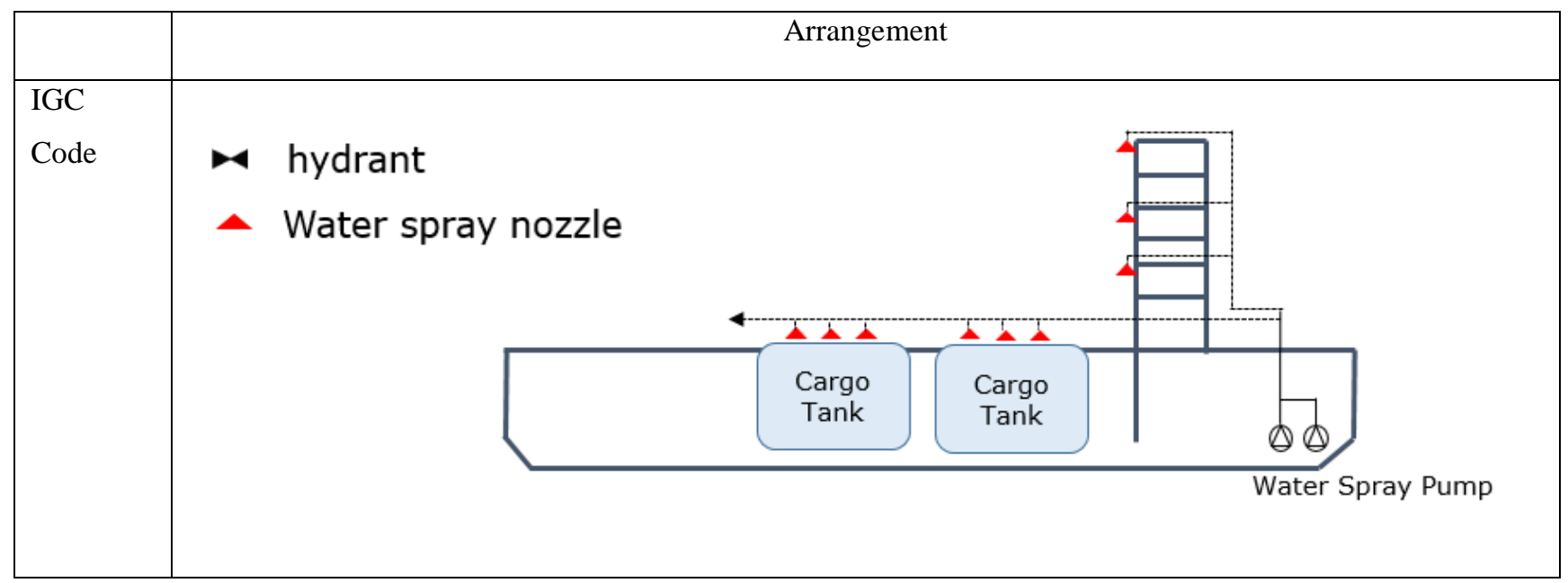




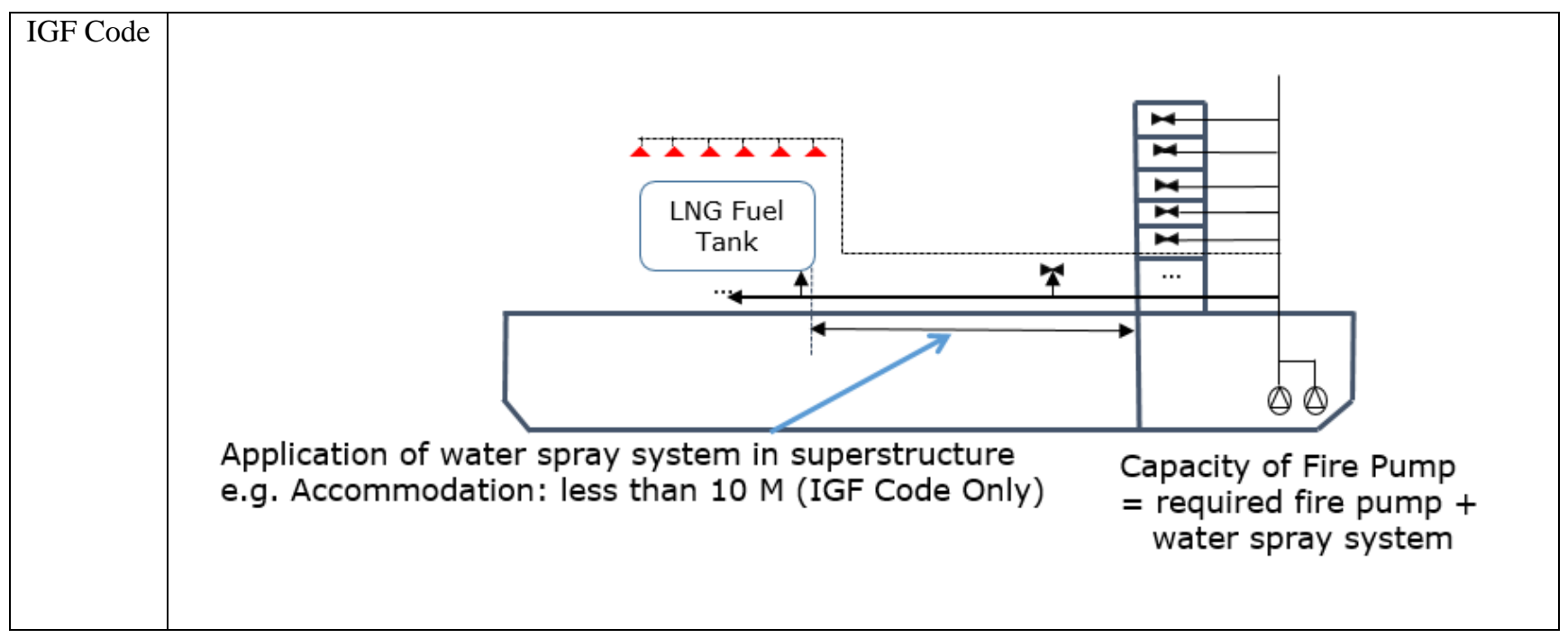

\subsubsection{Duct and double wall pipes in machinery space}

Regulatory imbalances can also be found in the safety requirements for the application of the duct and double wall pipes shown in Table 10.

Table 10. Safety requirements for fuel gas piping systems (duct and double wall pipes) in machinery space.

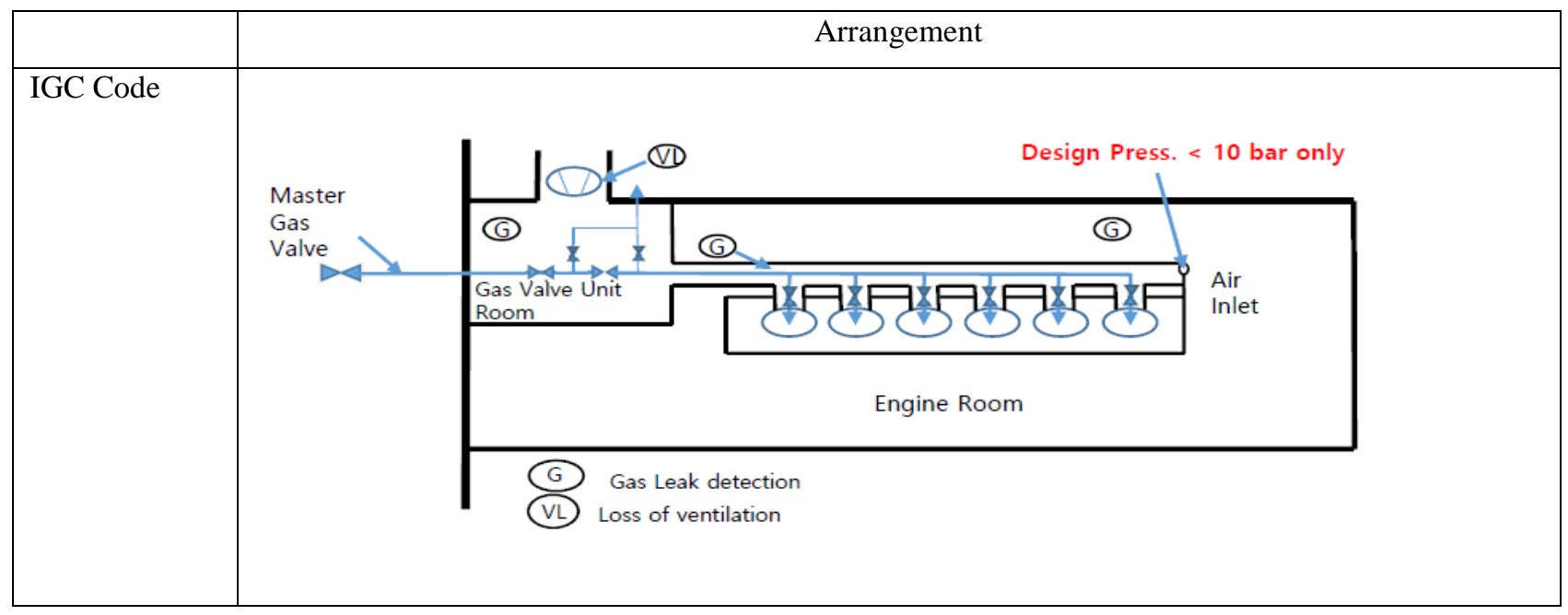




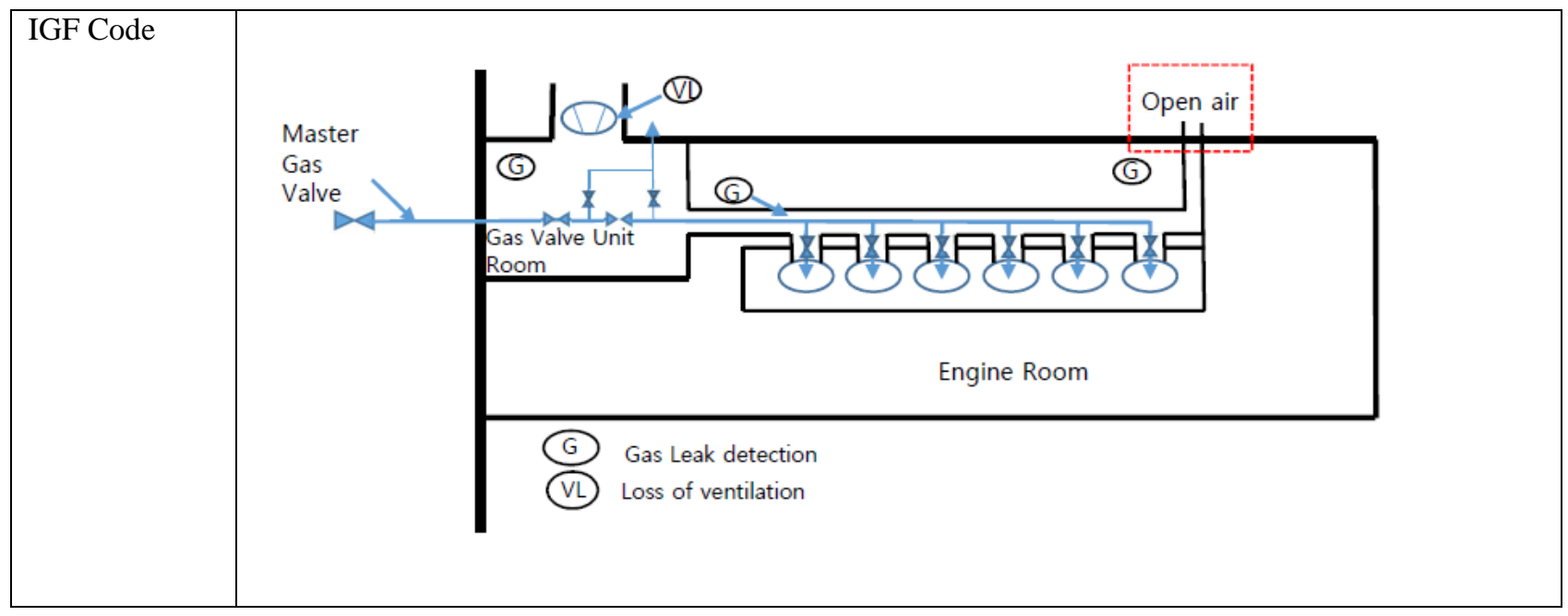

The gas safe machinery space concept in the IGC Code requires all gas piping in the machinery space to be enclosed in a gas-tight double barrier without openings to the engine-room. However, ventilation inlets in connection with the double pipe in the machinery space may be permissible for the lowpressure gas piping systems on the condition that gas detection system is installed in the surrounding engine room space (IMO 2011d).

According to the IGC Code 16.4.4.2, ventilation inlets and outlets to the double pipe should be led to cargo area in case of gas fuel with the operating pressure of $1 \mathrm{MPa}$ or greater (IMO 2014c). This means that the adverse effects of fuel gas pressure are taken into account in the IGC Code so as to minimise the potential risk of fire and explosion by placing the ventilation inlets and outlets in the cargo area.

On the other hand, the IGF Code has a somewhat different view on the coverage of this safety system. The unified interpretation of the IGF Code 13.8.3 with regard to ventilation inlet for double wall piping or duct is that the ventilation inlet for the double wall piping or duct should be located in a nonhazardous area having the open air and away from ignition sources (IMO 2016d). This implies that air inlets for the annular space and the gas valve unit room should be located in an open space for both low pressure and high-pressure gas fuel.

This interpretation (IMO 2016a) is based on:

- The machinery space contains multiple ignition sources. Consequently, even in gas safe machinery spaces, permitting ventilation inlets to draw air from the machinery space may not be 
the best of options;

- Inlets to ventilation systems for the hazardous area zone 1 cannot be located in the machinery space;

- The actual ventilation rate is not defined by the requirement for 30 air changes per hour in the annular space between the inner and outer pipe(IGF 9.6.1.2). Consequently, an assumption that the ventilation rate will be larger than the leakage rate to prevent gas in the machinery space cannot be made.

On the other hand, IMO Sub-Committee on Carriage of Cargoes and Containers (CCC) was of the view that the interpretation text for IGF Code is not necessarily compatible with the IGC Code. Therefore, the LNG fuelled ships are subject to some different arrangements for ventilation inlets of the double wall piping and the duct (IMO 2016b). However, it was our thought that this regulatory disparity would leave the potential for future inconsistency, misinterpretation and misunderstanding in a fast expanding sector of the industry.

\subsubsection{Duct and double wall pipes outside machinery space}

For LNG carriers, the secondary enclosure of the on-deck liquid fuel gas pipe between the fuel gas pump in cargo tank and the high pressure pump in compressor room is not required, whereas this safety measures should be applied to the equivalent pipe in case of LNG fuelled ships to comply with the amended IGF Code 9.5.6 (IMO 2017a, 2017b) which will be adopted at $100^{\text {th }}$ session of Maritime Safety Committee. Table 11 illustrates such a difference between the two Codes.

Table 11. Safety requirements for piping systems outside machinery space.

\begin{tabular}{|l|l|}
\hline & Arrangement \\
\hline
\end{tabular}




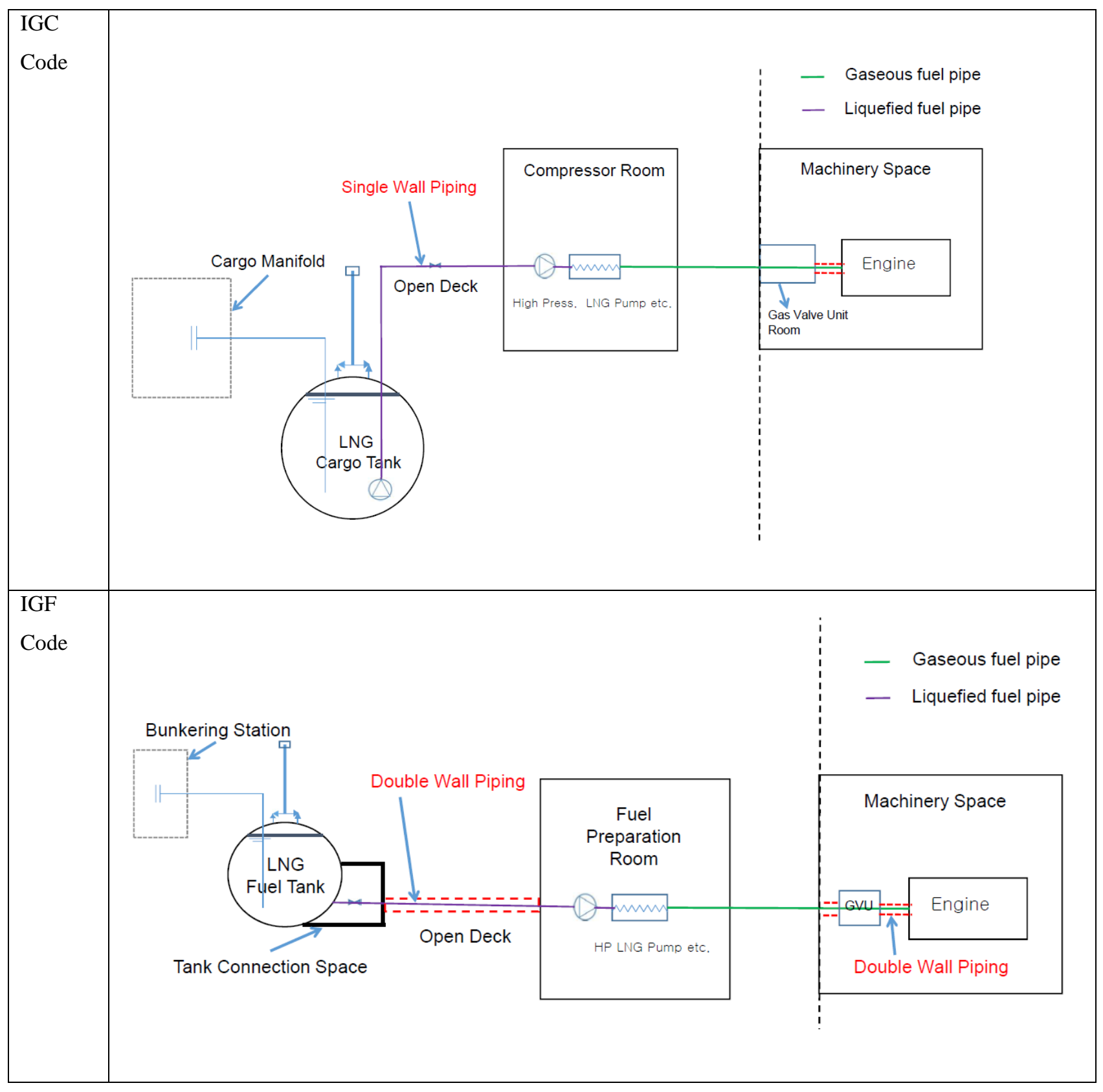

\subsubsection{Ventilation}

While both Codes refer to IEC 60092-02:1999 regarding the requirements of ventilation, the IGF Code alone requires the mechanical ventilation system to be fitted to the tank connection space, ESD protected machinery space(IGF Code 13.4.1)(IMO 2014c; IMO 2015c). The safety requirements pertinent to mechanical ventilation systems provided in the IGF Code are represented in Table 12.

Table 12. Safety requirements for ventilation system 
The level of the redundancy for ventilation fan in fuel preparation room is equivalent to the compressor room in LNG carriers. The IGF Code also provides specific parts with some flexibility concerning

\begin{tabular}{|l|l|l|}
\hline \multicolumn{1}{|c|}{ Items } & \multicolumn{1}{|c|}{ IGC Code } & \multicolumn{1}{c|}{ IGF Code } \\
\hline $\begin{array}{l}\text { Fuel Preparation Room or } \\
\text { Compressor Room }\end{array}$ & $\begin{array}{l}\text { Minimum 30 time air changes per hour } \\
\text { (IGC Code 12.1.3) }\end{array}$ & $\begin{array}{l}\text { Minimum 30 time air changes per hour(IGF Code } \\
13.6)\end{array}$ \\
\hline Tank connection space & N/A & $\begin{array}{l}\text { Minimum 30 time air changes per hour(IGF Code } \\
13.4)\end{array}$ \\
\hline ESD protected machinery & N/A & $\begin{array}{l}\text { Minimum 30 time air changes per hour(IGF Code } \\
13.5 .2)\end{array}$ \\
\hline Ducts and double pipes & - Minimum 30 air changes per & $\begin{array}{l}- \text { the reduction to 10 air changes per hour is } \\
\text { permitted if automatic filling of the duct with } \\
\text { hour(except when supplying the inert } \\
\text { gas to double pipes) (IGC Coden is arranged upon detection of gas(IGF } \\
16.4 .3 .2)\end{array}$ \\
\hline
\end{tabular}

ventilation capacity for duct and double wall pipe. The capacity of the ventilation can be 30 time air changes per or less hour if ensuring a flow velocity of minimum $3 \mathrm{~m} / \mathrm{s}$ (IGF Code 13.8.4). Furthermore, the reduction to 10 time air changes per hour is permitted if automatic filling of the duct with nitrogen is arranged upon detection of gas(IGC Code 9.6.1.2) (IMO 2015c).

Given the uniform condition between LNG fuelled ships and LNG carriers, the fact - that the mitigation requirements for the ventilation capacity of the double walled pipe specified in the IGF code are inconsistent with the requirements of the IGC code - appears to lead to a future debate on ventilation requirement.

\subsection{Cargo manifold/bunkering station}

The installation of the vapour return line is considered optional for LNG fuelled ships, whereas it is mandatory to the vessels subject to the IGC Code as described in Table 13.

Table 13. Requirement for vapour return line. 


\begin{tabular}{|c|c|c|}
\hline Items & IGC Code & IGF Code \\
\hline Vapour return & $\begin{array}{l}\text { - Vapour return line is to be } \\
\text { provided(IGC Code 5.6.3) }\end{array}$ & $\begin{array}{l}\text { - Vapour return line is optional } \\
\text { - Dry disconnect type with additional safety dry } \\
\text { breakaway coupling/self-sealing for quick release } \\
\text { (IGF Code } 8.4 \text { ) }\end{array}$ \\
\hline Emergency shut-down & ESD-1 or ESD-2 & ESD-2 only \\
\hline Fire fighting system & $\begin{array}{l}\text { dry powder monitor(s) (IGC Code } \\
11.4 .3 \text { ) }\end{array}$ & $\begin{array}{l}\text { - Permanent dry chemical powder fire- } \\
\text { extinguishing system (IGF Code 11.6.1) } \\
\text { - Portable dry powder fire extinguisher with at } \\
\text { least } 5 \mathrm{~kg} \text { capacity(IGF Code } 11.6 .2 \text { ) }\end{array}$ \\
\hline
\end{tabular}

For LNG carriers, the cargo manifold is located in the cargo area above the weather deck in accordance with the IGC Code and close to the mid-ship as practicable (SIGTTO 2011). On the other hand, for LNG fuelled ships, the location of bunkering station can be arranged to various locations depending on ship characteristics such as fuel tank location, ship type, nature of cargo etc.

In an emergency situation, cargo manifold for LNG carriers is controlled by one of the ESD-1 and ESD-2 defined in the SIGTTO Guideline (SIGTTO 2009). However, the bunkering system is required to be controlled by only ESD-2 systems such as safety dry breakaway coupling/self-sealing for quick release. Here are some details for ESD-1 and -2;

- ESD-1: Emergency shutdown stage 1 - shuts down the cargo transfer operation in a quick controlled manner by closing the shutdown valves and stopping the transfer pumps and other relevant equipment in ship and shore systems.

- ESD-2: Emergency shutdown stage 2 - shuts down the transfer operation (ESD-1) and uncouples the loading arms after the closure of both the ERS isolation valves.

The IGC Code simply requires the provision of dry powder monitor(s) to protect any load/unload connection area, whereas the IGF Code 11.6 requires the provision of permanently installed dry chemical powder fire-extinguishing system as well as a portable dry powder fire extinguisher with at least $5 \mathrm{~kg}$ capacity (IMO 2014c; IMO 2015c).

For LNG-fuelled ships, LNG bunkering is an inevitable process. The most established method of LNG bunkering is the transfer of LNG from the LNG terminal to the receiving vessel in a manner similar to the loading and unloading of LNG cargo into the cargo tank. 
However, due to the lack of terminal infrastructure, several alternatives have emerged, such as the use of LNG tank trucks, LNG feeders or portable LNG tanks which may be pertinent to higher potential hazards than the conventional terminal bunkering.

Although IMO and reginal organizations have developed a serise of safety requirements, particularly the presence of watch keeper, the installation of ESD system and firefighting systems, the failure of these systems cannot be ignored. The current rules and regulations concerning the design and operation of LNG bunkering system lack specific quantified guidelines.

ISO/TS 18683 (ISO 2015) recommends establishing a safety exclusion zone around the LNG bunkering areas access to which is to be restricted to all non-essential personnel during bunkering in order to minimize the probability of ignition, thereby the threat to human lives if an accident. Such a safety exclusion zone includes the supply point and the onboard bunkering station (Jeong et al. 2017).

Given the fact that the IGC Code for LNG carriers, or related standards, does not specify the need of the safety zone for LNG cargo transfer, the safety requirements on the LNG bunkering may be considered stringent.

\subsection{Miscellaneous systems}

In this part, the gas analysis identifying the differences or discrepancies of the control, monitoring and safety system between two(2) Codes is provided.

\subsubsection{Temperature indicator}

LNG bunkering may encounter the potential risk of rapid fuel tank pressurization by the mixing of different temperature/properties of fuels which may be produced/supplied from different areas. In this context, the temperature indicator in LNG fuel tank is a key equipment to prevent the risk of a rapid rise of pressure caused by mixing fuels with different temperature before a bunkering operation. Besides, it is also used to prevent stratification phenomenon during the fuel agitation operation when some different temperature layers are confirmed after bunkering (IMO 2015a).

Therefore, the number of temperature indicators to be installed in LNG fuel tank is more than that of LNG cargo tank (IMO 2015b, 2015c). According to IGF Code 15.4.11, Type C tank supplied with a vacuum insulation system and pressure build-up fuel discharge unit are excluded because the fuel in 
this tank may not age by not ejecting of the boil-off gas (BOG) during the voyage and bunkering. Whereas, the application of this requirement of temperature indicator in the IGC Code is the same for all tank type including the Type C.

\subsubsection{Gas detection}

The IGF Code requires a gas dispersal analysis or physical smoke test to decide the best arrangements for gas detectors, but the IGC Code does not specify such a requirement (IMO 2014c; IMO 2015c). The setting value for gas detection is also stricter at 20\% Lower Explosion Limit (LEL) in the IGF Code than 30\% LEL in the IGC Code. The IGC Code 13.6.19 requires two portable gas detection equipment or more while the IGF Code 15.8 .6 does not specify a mandatory number.

\section{Discussion}

Despite the increasing popularity of LNG carriers and LNG fuelled ships, the current international Codes seem to need some improvement in terms of achieving uniform safety requirements. There is some disharmony across the provisions which has never received thorough investigations.

Typically, the design of LNG fuelled ships is analogous to conventional LNG carriers in many aspects, such as the arrangement of LNG storage tanks and the loading/unloading systems and their operating procedures. It was viewed that the regulatory inconsistencies across the two Codes may cause the different application of safety requirements to the exactly-same systems, leading to significant differences in the design of LNG carriers and LNG fuelled ships. In particular, LNG carrier with gas engines is also regarded as the same type as the LNG fuelled ship. However, such a LNG carrier is only subject to the IGC Code, but not the IGF Code. Given this, regulatory discrepancies between the two Codes may aggravate ambiguity. It is, therefore, necessary to promote transparency in the disciplined regulations.

In this context, a particular emphasis of this paper was placed on overviewing the regulatory gaps between the IGC and the IGF Codes in an effort to contribute to unified implementation for discordant provisions in these Codes. Hence, this paper suggests that the IMO should take a proactive action to narrow the gaps between the two Codes by proposing revisions or unified interpretations for the discords discussed in the previous chapters; it may either need to revise the IGC Code according to the 
IGF Code or vice versa in order to harmonize both codes based on proper maritime architecture and engineering principles and practices.

The main base of the IGF Code for ships using LNG as a marine fuel is the experience and knowledge of similar systems of LNG carriers. Therefore, they particularly need to be reviewed and revamped based on proper systematic risk assessment of the LNG fuelled ships.

In recent years, IMO regulations have become increasingly diverse and complicated; thereby stakeholders encounter difficulties in designing and adapting them to ships and even costly. For instance, shipyards, who have extensive experience in designing LNG carriers, are confused about applying some different safety regulations to the same system (e.g., the engine room system) when constructing LNG fuelled ships. This gap is also the same for the Flag State and Classification Society which approves ships. In this context, this paper is believed to be a useful guide in enhancing a general understanding of the similarities and inconsistencies between the two Codes. It may help stakeholders to identify further actions to be taken, while to prevent ship designers from becoming confused by regulatory differences.

\section{Conclusions}

Through the gap analysis, it was found that the LNG-fuelled-ships are generally subject to a higher level of safety requirements by the IGF Code, compared to the equivalences for LNG carriers by the IGC Code. It seems to have originated from the gap between the brevity of LNG fuelled ships and LNG carriers with the perfect safety records.

However, it was also thought that some regulations in these Codes lacked clear technical justification, whereas some others appeared to be too severely applied, disregarding the successful safety record of LNG carriers over the several decades.

Given the different risk natures between delivering LNG as cargo and using LNG as fuel, the two Codes may not be able to be fully idential; if a clear technical justification is provided, different regulations may be acceptable. However, it should be noted that the eqaul level of safety requirements must be applied at least where the same systems and arrangements are applied. The disparity in the safety requirements for the engine room systems can be a good example.

The paper suggests that the IMO should consider these findings, taking into account both experience 
and technical developments when the IMO periodically review these Codes and consider to amend the regulation in the Codes. In particular, the following parts of two Codes were proposed to go through a rigorous revision for bridging the gaps of the safety requirement for the engine room system: concept of machinery space (section 3.2), the stress analysis on piping system (section 3.4.1) and the safety requirements for duct and double wall pipe (section 3.4.3) and ventilation (section 3.4.5) discussed in this paper.

\section{Acknowledgement}

The authors would like to express their gratitude to Association of Asian Classification Societies (ACS) members, particularly Korean Register of Shipping, China Classification Society, Indian Register of Shipping, for their valuable support, comments and suggestions. They have contributed considerably to this research. In addition, the authors have to thank the Korean Ministry of Oceans and Fisheries for its efforts to ensure this paper was submitted to the CCS Sub-committee of IMO and circulated to the member states as an information document.

\section{References}

1. Arnsdorf I. 2013 Dec 4. Shell, GE to build nation's first LNG fueling stations for cargo ships. Bloomberg News. [accessed 2018 May 5].

https://fuelfix.com/blog/2013/12/04/shell-ge-to-build-nations-first-lng-fueling-stations-forcargo-ships/

2. Aronson JD, Westermeyer W. 1982. Us public and private regulation of LNG transport. Mar Policy. 6(1):11-26.

3. Corkhill M. 2017 Apr 24. The world's LNG-fuelled ships on order. LNG World Shipping. [accessed 2017 Sep 25].

http:/ / www.lngworldshipping.com/news/view,the-worlds-lngfuelled-ships-onorder-2017_47089.htm.

4. Davies P, Fort E. 2013. LNG as a marine fuel: Likelihood of LNG releases. J Mar Eng Technol. 
12(3):3-10.

5. DNVGL. 2018. LNG regulatory update "Best fuel of the future", conference \& study tour

6. IGU. 2018. 2018 World LNG Report. World Gas Conference Edition.

7. IMO. 2009. MSC 285(86). Interim guidelines on safety for natural gas-fuelled engine installations in ships. London: International Maritime Organizaion.

8. IMO. 2010. Comments on the report of the Correspondence Group on the Development of the Draft International Code On Safety For Gas-Fuelled Ships (IGF Code). BLG 15/6/1(France).

9. IMO. 2011a. Development of Provisions For Gas-Fuelled Ships. Report of the working group (Part 1). BLG 15/WP.5.

10. IMO. 2011b. Development of Revised IGC Code. Report of the correspondence group. BLG $16 / 7$.

11. IMO. 2011c. Proposals for modifications to the draft IGF Code. BLG 16/6/2(Japan).

12. IMO. 2011d. Proposal for modifications to the draft revised IGC Code. BLG 16/7/2(Norway).

13. IMO. 2011e. Report to the Maritime Safety Committee and the Marine Environment Protection Committee. BLG 15/19

14. IMO. 2012a. Report to the Maritime Safety Committee and the Marine Environment Protection Committee. BLG 16/16

15. IMO. 2013a. Development of risk-based distance criteria for gas fuel tanks for inclusion in the draft IGF Code, SDC 1/24(Norway)

16. IMO. 2013b. Harmonizing distance criteria for gas fuel tanks and assumed penetration depth providing appropriate collision protection and damage stability, SDC 1/24/4(CESA)

17. IMO. 2013b. Report of the Maritime Safety Committee on its Ninety - Second Session,. MSC $92 / 26$.

18. IMO. 2014a. Report of the Maritime Safety Committee, SDC 1/26

19. IMO. 2014b. Report of the Maritime Safety Committee on its Ninety - Fouth Session,. MSC 
$94 / 21$.

20. IMO. 2014c. International Code of the Construction and Wquipment of Ships Carrying Liquefied Gases in Bulk(IGC Code), Resolusion MSC.370(93) adopted on 22 May 2014

21. IMO. 2015a, Measures for bunkering safety operation, MSC 95/3/14(Japan)

22. IMO. 2015b. Report of the Working Group, Adoption of IGF Code. MSC95/WP.7

23. IMO. 2015c. International Code of Safety for Ships Using Gases or Other Low-flashpoint Fuels(IGF Code), Resolusion MSC.391(95)

24. IMO. 2015d. Editorial clarifications needed in order to ensure homogeneous application of risk assessment in conjunction with part A-1 of the draft IGF Code, MSC95/3/15 (China, Germany, Japan, Republic of Korea, Spain and CESA)

25. IMO. 2016a. Draft unified interpretations on the International Code of Safety for Ships Using Gases or Other Low-Flashpoint Fuels (IGF Code). CCC 3/10/1(IACS).

26. IMO. 2016b. Report of the Working Group, Amendments to The IGF Code and Development Of Guidelines For Low-Flashpoint Fuels. CCC 3/WP.3.

27. IMO. 2016c. Report to the Maritime Safety Committee and the Marine Environment Protection Committee. CCC 3/15.

28. IMO. 2016d. Unified Interpretations of the IGF Code. MSC.1/Circ.1558

29. IMO. 2017a. Proposed amendments to the IGF Code. CCC 4/3/1(IACS)

30. IMO. 2017b. Report to the Maritime Safety Committee and the Marine Environment Protection Committee. CCC 4/12.

31. ISO. 2015. Guidelines for systems and installations for supply of LNG as fuel to ships. Geneva, Switzerland.

32. Fernandez IA, Gomez MR, Gomez JR, Insua AB. 2017. Review of propulsion systems on LNG carriers. Renew Sust Energ Rev. 67:1395-1411.

33. Saleem A, Farooq S, Karimi IA, Banerjee R. 2018. A CFD simulation study of boiling mechanism and BOG generation in a full-scale LNG storage tank. Comput Chem Eng. 
115:112-120.

34. Jeong B, Lee BS, Zhou P, Ha S. 2017. Evaluation of safety exclusion zone for LNG bunkering station on LNG-fuelled ships. J Mar Eng Technol. 16(3):121-144.

35. Mankabady S. 1979. Financing LNG carriers. Mar Policy. 3(3):225-231.

36. Nwaoha T, Yang Z, Wang J, Bonsall S. 2013. A fuzzy genetic algorithm approach for analysing maintenance cost of high risk liquefied natural gas carrier systems under uncertainty. J Mar Eng Technol. 12(2):57-73.

37. Øyvind P, Erikstad SO. 2017. A two-stage optimization approach for sulphur emission regulation compliance. Marit Policy Manag. 44(1):94-111.

38. Rahim MM, Islam MT, Kuruppu S. 2016. Regulating global shipping corporations' accountability for reducing greenhouse gas emissions in the seas. Mar Policy. 69:159-170.

39. Ryuichi S, Usami T, Furuichi M, Teranishi H, Kato H. 2018. How do the new shipping routes affect Asian liquefied natural gas markets and economy? Case of the Northern Sea Route and Panama Canal expansion. Marit Policy Manag. 45(4):543-566.

40. SIGTTO. 2009. ESD Arrangements \& Linked Ship/ Shorre Systems For Liquiefied Gas Carriers.

41. SIGTTO. 2011. Recommendations for Manifolds for Refrigerated Liquefied Gas Carrier. 